\title{
Analysis of ternary mixture of anti-Parkinsonism drugs by capillary electrophoresis in pharmaceutical dosage forms
}

Wael Talaat ( $\nabla$ wtalaat2017@gmail.com)

Damanhour University Faculty of Pharmacy

Hytham Ahmed

Department of Pharmaceutical Analytical Chemistry, Faculty of Pharmacy , Menofia University, Egypt

\section{Nahla Salama}

National Organization for Drug Control and Research

\section{Research article}

Keywords: anti-Parkinsonism drugs; capillary electrophoresis; Photodiode array detector

Posted Date: August 21st, 2019

DOI: https://doi.org/10.21203/rs.2.12924/v1

License: (a) (i) This work is licensed under a Creative Commons Attribution 4.0 International License. Read Full License 


\section{Abstract}

A simple CZE method was developed for the analysis of ternary anti-Parkinsonism mixture, levodopa, carbidopa and entacapone. The compounds were simply separated and measured using an untreated fused-silica capillary with $75 \mu \mathrm{m}$ internal diameter and $85 \mathrm{~cm}$ total length, with effective length of $70 \mathrm{~cm}$.. Background electrolyte composed of $20 \mathrm{mM}$ phosphate buffer of $\mathrm{pH} 7.5$ was used under an applied voltage of $15 \mathrm{kV}$. Photodiode array detector (PDA) was used to identify each compound at different wavelength to obtain high sensitivity. The present method was conducted to the analysis of the ternary mixture in pharmaceutical preparations. The analytical results proved the linearity $(r 2 \geq 0.9995)$, accuracy, precision (\% RSD < 2).

\section{Introduction}

Parkinsonism is a disease affecting central nervous system due to imbalance of dopamine and results in tremor ,movement disorder, bradykinesia, and postural instability. ${ }^{[1,2]}$. Entacapone is an inhibitor of catechol-O-methyltransferase (COMT). Entacapone is co administered with levodopa and carbidopa which is inhibitor to aromatic amino acid decarboxylase ${ }^{[3]}$. Figure 1 shows the structural formula and IUPAC names of entacapone, levodopa and carbidopa [4].

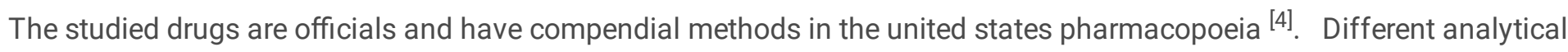
methods have been published for the simultaneous analysis of entacapone, levodopa and carbidopa. The literatures includes spectrophotometric method ${ }^{[5]}$, different separation techniques like HPLC ${ }^{[6-11]}$, HPTLC [12], LC-MS ${ }^{[13]}$ and CE ${ }^{[14]}$. There is only one published capillary electrophoresis method for the analysis of the studied ternary mixture. The reported method is somehow more complicated than the proposed method as it needs the addition of cyclodextrin to improve the resolution the compounds. The drugs under research are simply resolved and estimated by the simple phosphate buffer introduced by our methods. The proposed method is conducted through $20 \mathrm{mM}$ phaospahte buffer pH 7.5, injection time 6 $s$ and voltage $+15 \mathrm{kV}$.

\section{Experimental}

\section{Chemicals and reagents}

Levodopa , carbidopa and entacapone were from NODCAR (Egypt). Each Stalevo® tablet (Batch no.: 1530981; Novartis Pharma AG, Switzerland) should contain 200, 100 and 25 mg of entacapone, levodopa and carbidopa, respectively. Methanol (HPLC grade) was obtained from Sigma-Aldrich. Sodium dihydrogen phosphate, 85\% orthophosphoric acid, sodium hydroxide, hydrochloric acid, were purchased from Wako Pure Chemical Industries (Osaka, Japan). Phosphate buffer $(20.0 \mathrm{mM})$ was prepared in ultra-pure deionized water. The $\mathrm{pH}$ was adjusted at 7.5 using sodium hydroxide or phosphoric acid. Stock solutions of concertation $1.0 \mathrm{mg} / \mathrm{mL}$ of levodopa and carbidopa were prepared in water, while entacapone solution was prepared in methanol. The running buffer was used to dilute the stock solutions to get the final concentrations in the linear range.

\section{Apparatus and conditions}

Agilent CE instruments 7100 series (Agilent Technologies, Waldbronn, Germany) with diode array detector. An untreated fused-silica capillary was used for the analysis and was obtained from Agilent Technologies with $75 \mu \mathrm{m}$ internal diameter and $85 \mathrm{~cm}$ total length, $70 \mathrm{~cm}$ effective length. Treatment of the capillary was performed with $1.0 \mathrm{M}$ sodium hydroxide, ultra-pure deionized water and running buffer for $60 \mathrm{~min}, 30 \mathrm{~min}, 30 \mathrm{~min}$ respectively. The previous treatment was repeated in each day for $10 \mathrm{~min}$. To obtain good reproducibility, the capillary was flushed before each run for 3 min by $0.1 \mathrm{M}$ sodium hydroxide, ultra-pure deionized water and for $5 \mathrm{~min}$ by the buffer. 
The method was conducted using $20 \mathrm{mM}$ phaospahte buffer with $\mathrm{pH} 7.5$ and a potential of $+15 \mathrm{kV}$ at $25^{\circ} \mathrm{C}$. The samples were hydrodynamically injected at the anodic side with 50 mbar for $6 \mathrm{~s}$.

The analytes were detected at $210 \mathrm{~nm}, 280 \mathrm{~nm}$ and $380 \mathrm{~nm}$ for carbidopa , levodopa and entacapone respectively. A Balance, Scaltec SPB 31 Balance Calibration (Scaltec Instruments GmbH, Heiligenstadt, Germany), Sonicator, USR 3 Sonicator (JULABO, Seelbach, Germany). A LAQUA, pH-Meter (Horiba, Ltd. Kyoto, Japan).

\section{General procedure and calibration curve}

Working solutions of entacapone, levodopa and carbidopa of concentrations within the linearity range were prepared by diluting aliquots of the stock solutions with running buffer. The optimum conditions of analysis were achieved at $25^{\circ} \mathrm{C}$ using $20 \mathrm{mM}$ phosphate running buffer, pH 7.5 and applied voltage of $+15 \mathrm{kV}$. The analytes were detected at 210,280 and $380 \mathrm{~nm}$ for carbidopa, levodopa and entacapone respectively. The calibration curves were constructed by plotting the peak area versus the analyte concentration.

\section{Analysis of tablets}

The extraction was challenging due to the different solubilities of the studied drugs in water and methanol. Levodopa is soluble in water but is not in methanol. Carbidopa is water and methanol soluble. While entacapone is methanol soluble and sparingly soluble in water. Different ratios of water and methanol were studied to develop the best extraction of the three drugs. The high percentage of extraction was obtained upon using water: methanol $(30: 70, v / v)$.

Ten Stalevo tablets were individually weighed and finely powdered. In a $100 \mathrm{~mL}$ volumetric flask, an amount of the powder equivalent to the average weight of one tablet was placed and extracted by $80 \mathrm{~mL}$ of the extracting solvent. The solution was sonicated for $20 \mathrm{~min}$, filtered and dilution to the mark with the same mixture. Aliquots of the extract were transferred to $10 \mathrm{~mL}$ volumetric flasks and diluted with BGE to the mark so that the final concentrations will be in the linear concentration range.

\section{Results}

After optimization of the analytical method, it was found that the optimum parameters for the separation and estimation of the three drugs were achieved by running $20 \mathrm{mM}$ phosphate buffer of $\mathrm{pH} 7.5$ and voltage of $+15 \mathrm{kV}$ at $25^{\circ} \mathrm{C}$. Table 1 summarizes different optimization parameters. Figure 2 shows the electropherogram of the separated compounds. Raw materials and tables of the studied drugs were analysed by the present method and an acceptable results were obtained (Table 4,6).

\section{Discussion}

\section{Method optimization and development}

The optimum conditions were achieved by studying the separation parameters like the concentration of the running buffer, buffer $\mathrm{pH}$, the applied voltage and the capillary temperature. The different parameters were studied and optimized to reach high number of theoretical plates (NTP) and resolution (Table 1)

\section{The effect of buffer $\mathrm{pH}$}

The $\mathrm{pH}$ of the buffer significantly affecting the electromigration of analytes. The $\mathrm{pH}$ was optimized to stabilize both the migration velocity and electroosmotic flow of the analytes. The effect of phosphate buffer $\mathrm{pH}$ on the separation was investigated over the range of $5.5-7$. Borate buffer was used to study the effect of alkaline pH from 8 to 10 . The alkaline $\mathrm{pHs}$ from 8 to 10 result in overlap of carbidopa and entacapone. At low pHs, the entacapone peak area decreases. This 
reduced peak area is due to its low solubility in acidic $\mathrm{pH}$. Peak area increases as the $\mathrm{pH}$ increases. The $\mathrm{pH}$ selected was 7.5 at which high number of theoretical plates and good resolution were obtained.

\section{The effect of buffer concentration}

The effect of buffer concentration on electrophoretic separation is believed to its effect on both the electro osmotic flow (EOF) and the electric current. Different phosphate buffer concentrations (10-30 mM) were studied. As the concentration of the buffer increases, peak broadening obtained as a result of high migration times and electric current (Table 1). A concentration of $20 \mathrm{mM}$ was optimum and used in further progress.

\section{The effect of applied voltage}

The effect of applied voltage on the electrophoretic separation was investigated over the range from 10 to $20 \mathrm{kV}$. The electroosmotic flow (EOF) increases and the migration time decreases as the applied voltage increases A high current and hence joule heating increase when the applied voltage over $20 \mathrm{kV}$ (Table 1). The optimum applied voltage selected was 15 $\mathrm{kV}$ as it gave high resolution.

\section{The effect of injection time}

Investigating the pressure and time for hydrodynamic injections was done. A pressure of $50 \mathrm{mbar}$ was found suitable, as it provided the best peak shape. Pressure values $<50$ mbar yielded small peaks with very low response, and values $>50$ mbar yielded broad peaks. After the pressure was selected, the injection time was studied. A 6 s injection time was selected as optimum. Injection time $<6$ s yielded low peak responses and higher injection time yielded broad peaks. Both pressure and injection times had nearly negligible effect on the migration times of the drugs.

\section{The effect of capillary temperature}

The capillary temperature affects the viscosity of the running buffer and electroosmotic flow (EOF) so it has to be controlled. The effect of temperature was investigated over the range $20-30{ }^{\circ} \mathrm{C}$. The best resolution and reduced joule heating were obtained at $25^{\circ} \mathrm{C}$.

\section{Selection of the detection wavelength}

Detections were performed at $210 \mathrm{~nm}, 280 \mathrm{~nm}$ and $380 \mathrm{~nm}$ for carbidopa, levodopa and entacapone respectively to obtain maximum sensitivity.

\section{Validation}

The ICH guidelines ${ }^{[15]}$ were considered for the study of different validation parameters of the proposed method.

\section{Linearity and range}

The produced peak area and the concentrations in $\mu \mathrm{g} / \mathrm{mL}$ of the studied drugs were found to be linearly related. The main validation parameters are summarized in Table 2.

\section{Limits of quantitation and detection}

The ICH guide lines [15] provide two formula for the calculation of both LOQ and LOD. (Table 2). The limits of quantitation for the studied drugs were $1.48,3.2,2.15 \mu \mathrm{g} / \mathrm{mL}$ and the limits of detection were $0.5,1.06,0.71 \mu \mathrm{g} / \mathrm{mL}$ for levodopa, carbidopa and entacapone respectively.

$\mathrm{LOQ}=10 \mathrm{Sa} / \mathrm{b}$ and $\mathrm{LOD}=3.3 \mathrm{Sa} / \mathrm{b}$ 


\section{Precision and accuracy}

The assessment of intraday and interday precisions was performed. Three different concentrations of each drug were injected three times for each. The study was performed for three successive days. The small values of relative standard deviation (\% RSD) indicate high precision as shown in Table 3. The accuracy of the proposed methods was also high as indicated by the low value of percent relative error (\%Er) Table 3. The proposed method was satisfactory compared with the compendial methods ${ }^{[4]}$. The results are shown in (Table 3 ) and also table 4.

\section{Specificity}

Each of the studied compounds were specifically analyzed by the proposed CE method. The specificity was proved by injecting a mixture of the working concentration of the studied drugs. The drug peaks were eluted at migration times of 5.6, 6.6 and 6.9 min for levodopa, carbidopa and entacapone respectively fig.2.

\section{Robustness.}

The robustness of the method was evaluated by measuring the effect of small deliberate changes in $\mathrm{pH}$, phosphate buffer concentration, and applied voltage on the migration times of the analytes or the peak area. The results revealed that the small changes of the previous have no significant affect on either migration times or peak area. The results are shown in (Table 5).

\section{Application}

The studied drugs were simultaneously determined in their multicomponent tablets by the proposed CE method. The measurement of the studied compounds, levodopa, carbidopa and entacapone in Stalevo ${ }^{\circledR}$ tablets were successfully performed with high \% recovery good standard deviation as shown in Table 6.

\section{Conclusion}

A simple, accurate and precise capillary electrophresis method was established for the simultaneous analysis of levodopa, carbidopa and entacapone in their ternary mixture. The developed method was specific for the estimation of three antiParkinsonism drugs. The proposed method shows good validation criteria, and could be utilized in quality control laboratories. The proposed method is superior to the previously reported CE method as it is simple and do not require the use of cyclodextrin to improve the resolution. Also, no toxic chemicals were used in the methods which coincide with green chemistry.

\section{Declaration}

\section{Disclosure}

All authors read and approved the final manuscript. This paper is unique and is not under consideration by other publication and has not been published else where. The authors declare that they have no competing interest.

\section{Compliance with Ethical Standards:}

Availability of data and material: All needed data and material are available

Conflict of Interest: Author declares that he has no conflict of interest.

Funding: The authors did not receive fund for the work or for the publication 
Ethical approval: All procedures performed in studies involving human participants were in accordance with the ethical standards of the institutional and/or national research committee and with the 1964 Helsinki declaration and its later amendments or comparable ethical standards.

Authors' contributions: The authors contribute equally in this work.

\section{Acknowledgement}

The authors kindly acknowledge the National Organization for Drug Control and Research for the help towards providing the raw materials of the studied drugs.

\section{References}

[1] Aminoff M, Greenberg D, Simon R. Clinical Neurology 9/E, McGraw Hill Professional; 2015.

[2] Lisak R, Truong D, Carroll W, Bhidayasiri R. International Neurology: A Clinical Approach, Blackwell Publishing Ltd, Singapore; 2009.

[3] Christine C, Aminoff M. Clinical differentiation of parkinsonian syndromes: prognostic and therapeutic relevance, Am J Med. 2004; $117: 412-19$.

[4] U.S. Pharmacopeia, United States Pharmacopeia and National Formulary (USP 37-NF 32), Rockville, MD: US Pharmacopeia, 2014.

[5] Abdel-Ghany M, Hussein L, Ayad M, Youssef M. Investigation of different spectrophotometric and chemometric methods for determination of entacapone, levodopa and carbidopa in ternary mixture. SPECTROCHIM ACTA A. 2017;171:236-45.

[6] chandra B, Sarada N. A Simple Validated Stability Indicating RP-HPLC Method for the Determination of Three Antiparkinsonism Compounds in Oral Contraceptive Tablet Formulations. Int J Chemtech Res. 2017; 10 :11-15.

[7] Bhatnagar P, Vyas D, Sinha S, Chakrabarti T. Stability indicating HPLC method for simultaneous estimation of entacapone, levodopa and carbidopa in pharmaceutical formulation. J Chromatogr Sep Tech. 2015; 6 :1-6

[8] Madhavi S, Sultana S, Teja U, Nalluri B, DEVELOPMENT AND VALIDATION OF RP-HPLC-PDA METHOD FOR THE SIMULTANEOUS ESTIMATION OF LEVODOPA, CARBIDOPAAND ENTACAPONE IN BULK AND PHARMACEUTICAL DOSAGE FORMS. Indo Am j pharm. 2014; 4 : 22-29.

[9] Krishna V, Krishna K, Babu B, Development and validation of liquid chromatographic method for the simultaneous estimation of Levodopa, Carbidopa and Entacapone in the combined dosage form, J. Pharm. Res. 2014; 8 : 281-288.

[10] Issa Y, Hassoun M, Zayed A, Application of high performance liquid chromatographic method for the determination of levodopa, carbidopa, and entacapone in tablet dosage forms. J Liq Chromatogr Relat Technol. 2011; 34 : 2433-47.

[11] Bugamelli F, Marcheselli C, Barba E, Raggi M. Determination of I-dopa, carbidopa, 3-0-methyldopa and entacapone in human plasma by HPLC-ED, J PHARMACEUT BIOMED. 2011; 54 : 562- 7.

[12] Gandhi D, Mehta P. Simultaneous RP-HPTLC method for determination of levodopa, carbidopa, and entacapone in combined tablet dosage form.JPC-J PLANAR CHROMAT. 2011; 24 :236-241.

[13] Ribeiro R, Gasparetto J, de Oliveira R, de Francisco T, Martins C, Cardoso M, Pontarolo R. Simultaneous determination of levodopa, carbidopa, entacapone, tolcapone, 3-0-methyldopa and dopamine in human plasma by an HPLC-MS/MS method, Bioanalysis2015; 7 :207-220. 
[14] Zeid A, Nasr J, Belal F, Kitagawa S, Kaji N, Baba Y, Walash M. Determination of six anti-Parkinson drugs using cyclodextrin-capillary electrophoresis method: application to pharmaceutical dosage forms, RSC Advances. 2016 ; 6 :1751930 .

[15] I.C.H.H.T. Guideline, Validation of analytical procedures: text and methodology Q2 (R1), International Conference on Harmonization, Geneva, Switzerland, 2005, pp. 11-12.

\section{Tables}

Table 1 :Optimization of the CE conditions for the separation of the studied drugs in mixture

\begin{tabular}{|c|c|c|c|c|c|c|}
\hline \multirow[t]{2}{*}{ Parameter } & \multicolumn{3}{|c|}{ NTPX10 $10^{5}$} & \multicolumn{2}{|c|}{ Resolution } & \multirow[t]{2}{*}{ Current $(\mu \mathrm{A})$} \\
\hline & LD & $\mathrm{CD}$ & EN & $\mathrm{LD} \& \mathrm{CD}$ & $\mathrm{CD} \& \mathrm{EN}$ & \\
\hline \multicolumn{7}{|l|}{ Buffer $\mathrm{pH}$} \\
\hline 5.5 & 1.8 & 3.22 & 4.61 & 11.2 & 2.2 & 35 \\
\hline 6.0 & 2.1 & 3.34 & 4.55 & 13.8 & 3.54 & 32 \\
\hline 6.5 & 1.9 & 4.1 & 4.82 & 15.5 & 4.6 & 29 \\
\hline 7.0 & 2.3 & 4.2 & 5.24 & 17.8 & 5.4 & 25 \\
\hline 7.5 & 2.33 & 4.1 & 5.42 & 20.1 & 5.8 & 21 \\
\hline \multicolumn{7}{|c|}{ Buffer Conc. (mM) } \\
\hline 10 & 1.5 & 2.77 & 5.1 & 7.3 & 1.11 & 22 \\
\hline 15 & 2.4 & 3.2 & 5.6 & 7.9 & 2.1 & 26 \\
\hline 20 & 2.3 & 2.8 & 5.8 & 8.8 & 3.2 & 31 \\
\hline 25 & 2.11 & 2.8 & 5.77 & 8.5 & 2.9 & 35 \\
\hline 30 & 2.33 & 3.1 & 4.81 & 8.1 & 2.8 & 40 \\
\hline
\end{tabular}

\begin{tabular}{|c|c|c|c|c|c|c|}
\hline \multirow[t]{2}{*}{ ırameter } & \multicolumn{3}{|c|}{ NTPX $10^{5}$} & \multicolumn{2}{|c|}{ Resolution } & \multirow[t]{2}{*}{ Current $(\mu \mathrm{A})$} \\
\hline & $\mathrm{LD}$ & CD & EN & LD\&CD & $\mathrm{CD} \& \mathrm{EN}$ & \\
\hline \multicolumn{7}{|c|}{ splied voltage $(\mathrm{kV})$} \\
\hline 1 & 2.22 & 4.4 & 6.3 & 6.5 & 1.3 & 15 \\
\hline ; & 3.4 & 4.55 & 6.71 & 7.2 & 2.4 & 20 \\
\hline ) & 3.2 & 5.3 & 6.88 & 7.9 & 3.9 & 27 \\
\hline ; & 3.11 & 5.4 & 6.64 & 7.7 & 4.2 & 33 \\
\hline
\end{tabular}

LD: Levodopa, CD : Carbidopa, EN: Entacapone

Optimum parameters: $20 \mathrm{mM}$ phaospahte buffer $\mathrm{pH} 7.5$, injection time $6 \mathrm{~s}$, voltage $15 \mathrm{kV}$ 
Table 2: Performance data for the determination of the studied drugs by the proposed CE method

\begin{tabular}{|c|c|c|c}
\hline Entacapone & Carbidopa & Levadopa & Parameter \\
\hline $5-50$ & $5-50$ & $5-50$ & Conc range, $\mu \mathrm{g} / \mathrm{mL}$ \\
& & & \\
\hline $42.5+1.3 \mathrm{C}$ & $30.2+1.4 \mathrm{C}$ & $17.8+2.3 \mathrm{C}$ & Regression equation \\
\hline 0.9995 & 0.9997 & 0.9997 & correlation coefficient \\
\hline 0.28 & 0.45 & 0.34 & Sa \\
\hline 0.054 & 0.024 & 0.05 & Sb $/ \mathrm{x}$ \\
\hline 2.1 & 1.41 & 1.22 & $\mathrm{LOD}$ \\
\hline 0.71 & 1.06 & 0.50 & $\mathrm{LOQ}$ \\
\hline 2.15 & 3.20 & 1.48 & \\
\hline
\end{tabular}

$\mathrm{Sa}=\mathrm{SD}$ of the intercept.

$\mathrm{Sb}=\mathrm{SD}$ of the slope.

Sy $/ \mathrm{x}=\mathrm{SD}$ of the residuals.

Table 3:Intra day and inter day precision for the proposed method for the determination of the studied drugs 


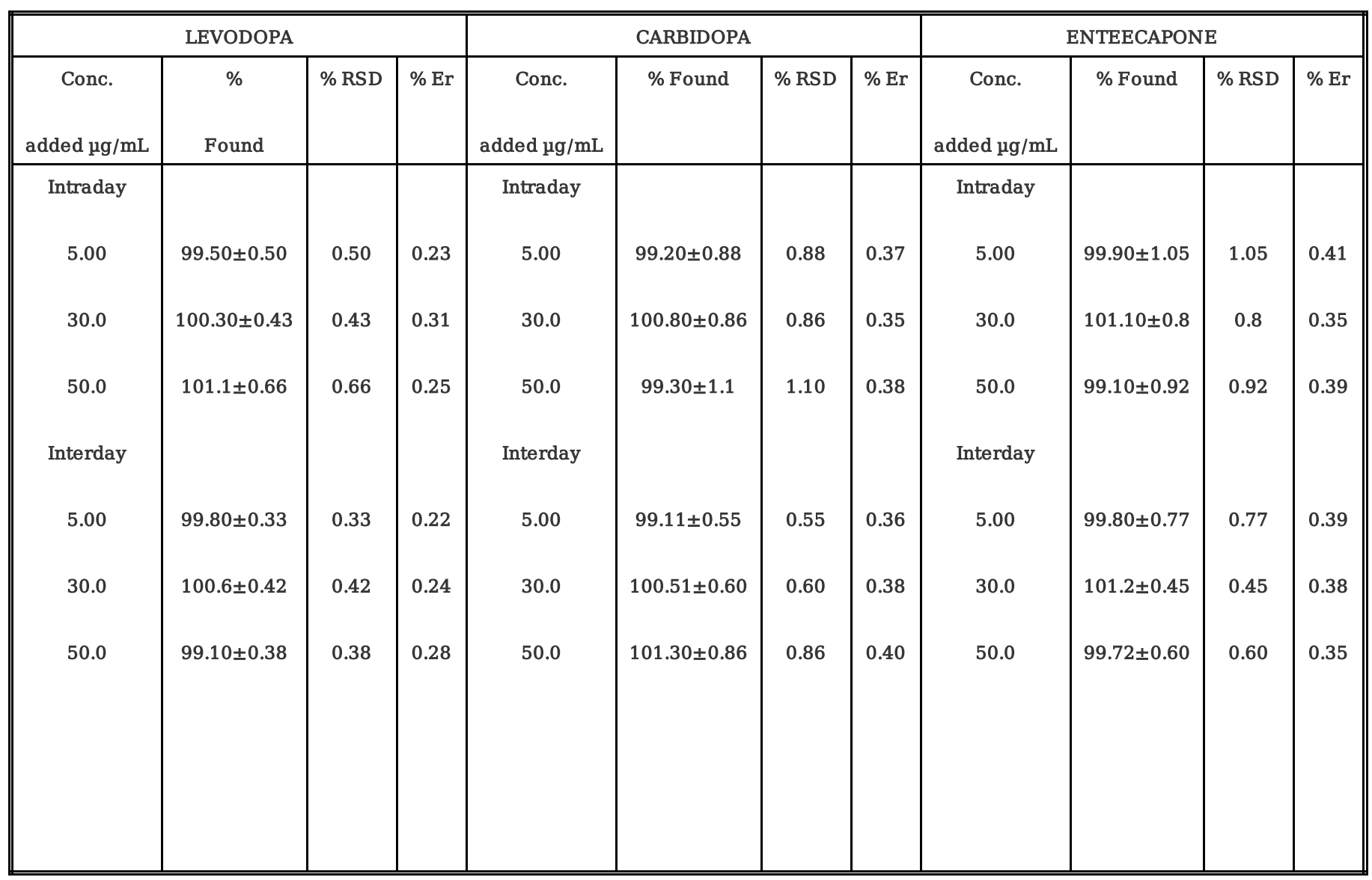

Each result is the average of three separate determinations.

Table 4: Application of the proposed and comparison method to determination of the studied drugs in raw material 


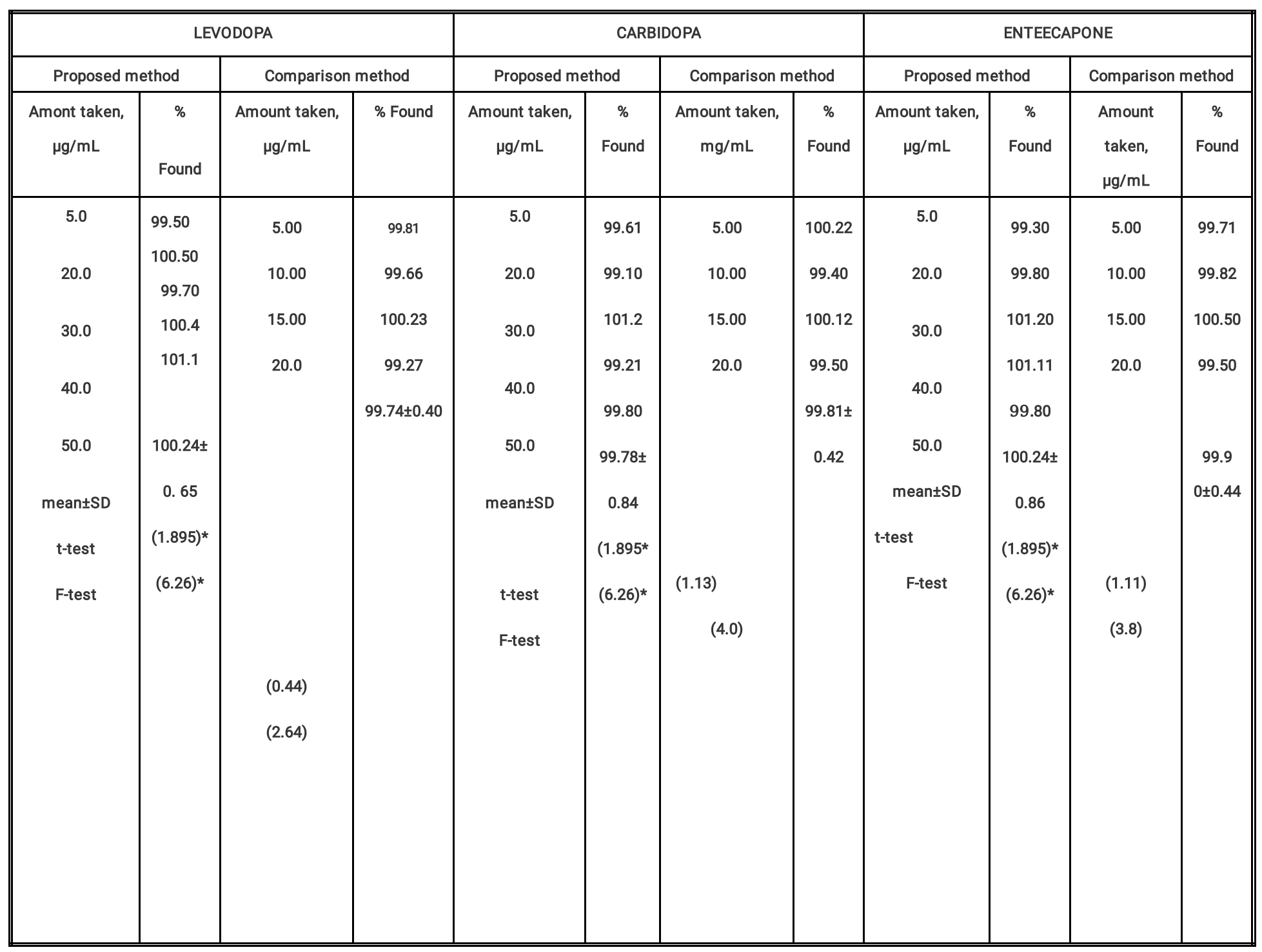

Each result is the average of three separate determinations.

Table 5. Robustness data 


\begin{tabular}{|c|c|c|c|}
\hline \multicolumn{3}{|c|}{ Migration times (min) } & \multirow[t]{2}{*}{ Parameters } \\
\hline ENTEECAPONE & CARBIDOPA & LEVODOPA & \\
\hline & & & Standard Buffer $\mathrm{pH}$ \\
\hline 6.1 & 6.8 & 5.4 & 7.3 \\
\hline 6.9 & 6.6 & 5.6 & 7.5 \\
\hline 7.0 & 7.1 & 5.8 & 7.7 \\
\hline & & & Buffer concocentration (mM) \\
\hline & & & 17 \\
\hline 7.3 & 6.8 & 6.2 & 20.0 \\
\hline 6.9 & 6.6 & 5.6 & 23.0 \\
\hline 6.3 & 6.1 & 5.1 & \\
\hline & & & Applied voltage $(\mathrm{kV})$ \\
\hline 7.3 & 6.8 & 5.7 & 13 \\
\hline 6.9 & 6.6 & 5.6 & 15 \\
\hline 6.5 & 6.2 & 5.2 & 17 \\
\hline
\end{tabular}

Table 6: Application of the proposed and comparison method to determination of the studied drugs in Stalevo tablets

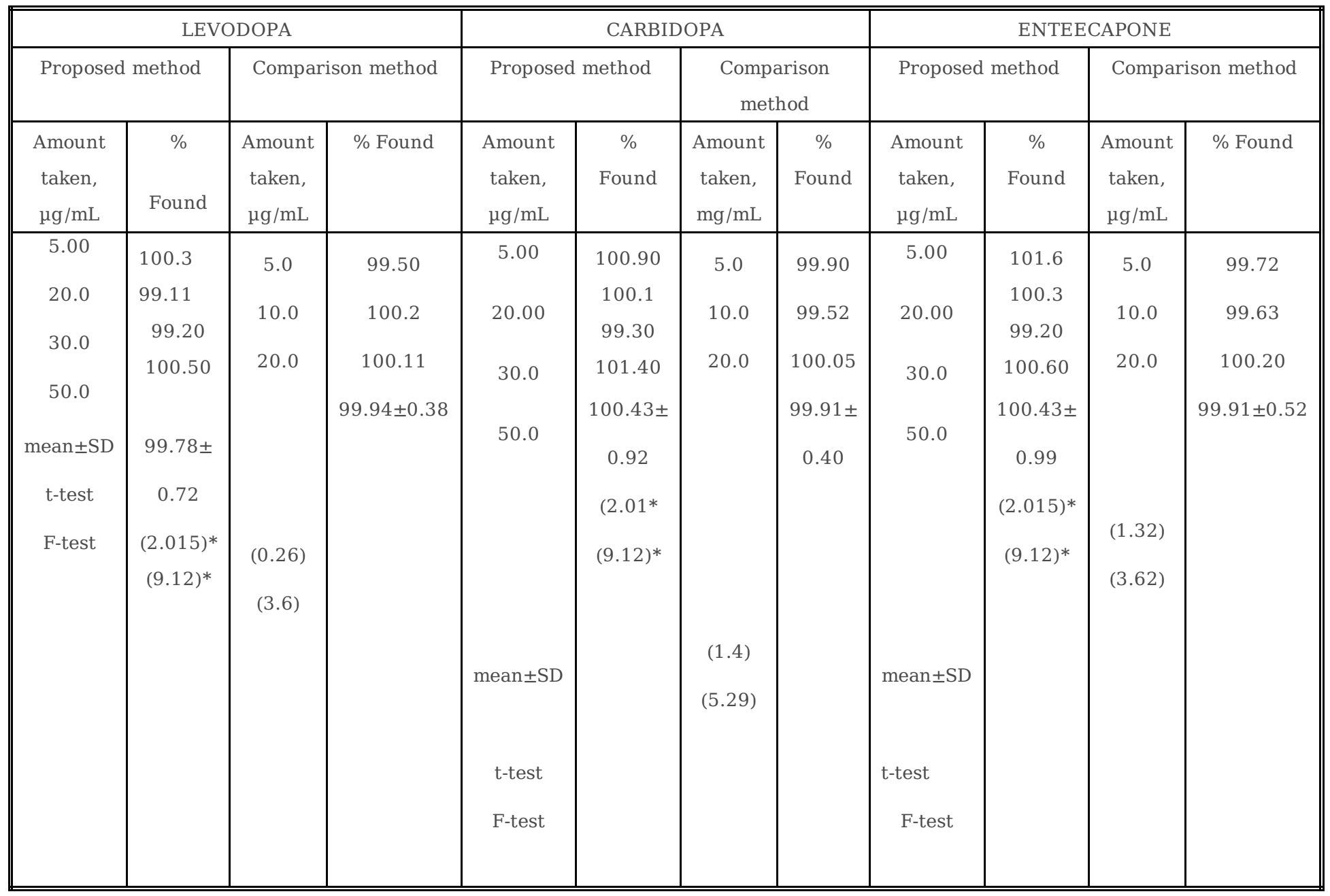




\section{Figures}<smiles>N[C@@H](Cc1ccc(O)c(O)c1)C(=O)O</smiles>

\section{L-3,4-dihydroxyphenylalanine}<smiles>C[C@](Cc1ccc(O)c(O)c1)(NN)C(=O)O</smiles>

\section{Carbidopa}

(2S)-3-(3,4-dihydroxyphenyl)-2-hydrazinyl-2-methylpropanoic acid

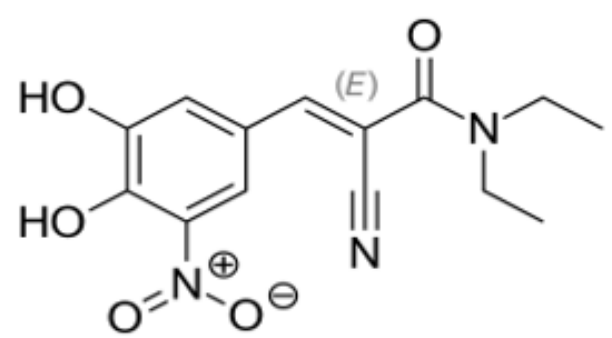

\section{Entacapone}

(E)-2-cyano-3-(3,4-dihydroxy-5-nitrophenyl)-N,N-diethyl-2-propenamide

\section{Figure 1}

Structural formula of the studied drugs 


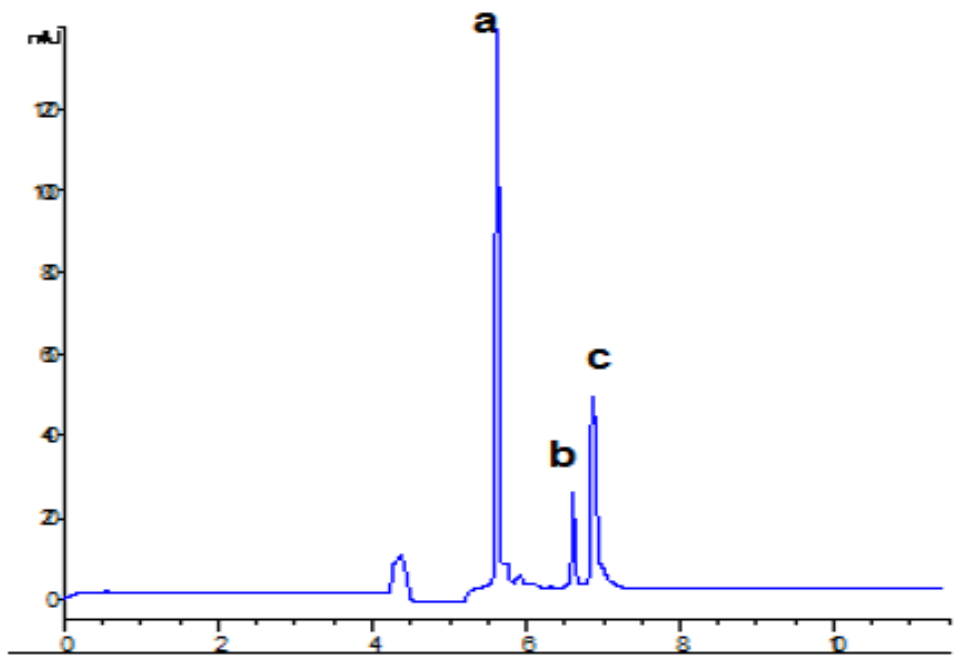

Figure 2

Electropherogram of(a) levodopa,(b) carbidopa and (c)entacapone 